\title{
Varis dışı üst gastrointestinal sistem kanamalı hastaların demografik ve klinik özellikleri
}

\author{
Demographical and clinical characteristics of the patients with non-variceal upper gastrointestinal \\ bleeding
}

Dilek BAHADIR ${ }^{1}$, Mehmet YALNIZ², Ulvi DEMIREL ${ }^{2}$, Cem AYGÜN² ${ }^{2}$ Ibrahim Halil BAHÇECIOĞLU²

Fırat Üniversitesi Tıp Fakültesi, Iç Hastalıklanı Ana Bilim Dalı ${ }^{1}$, Gastroenteroloji Bilim Dalı², Elazığ

\begin{abstract}
Giriş ve Amaç: Varis dışı üst gastrointestinal sistem kanaması sık karşılaşılan önemli acillerden biridir. Bu çalışmada varis dışı üst gastrointestinal sistem kanamalı hastalarda demografik ve klinik özelliklerin değerlendirilmesi amaçlanmıștır. Gereç ve Yöntem: 2005-2010 yılları arasında Varis dıșı üst gastrointestinal sistem kanaması nedeniyle endoskopi yapılarak izlenmiş olan toplam 330 hasta demografik özellikleri, etyoloji, risk faktörleri, tedavi ve mortalite yönünden retrospektif incelendi. Bulgular: 228'i (\%69.1) erkek, 102'si (\%30.9) kadın olup yaş ortalaması 59.9 (17-99) idi. Hastaların 84'ü (\%25.5) sigara, 12'si (\%7) alkol, 292'si (\%88.5) ilaç; (148'i (\%44.8) nonsteroid anti-inflamatuvar ilaç, 113'ü (\%34.2) aspirin) kullanıyordu. En sık hipertansiyon (n=96, \%29.1) olmak üzere eșlik eden hastallklar mevcuttu. Endoskopi hastalarn 156'sma (\%47.3) ilk 12 saatte, 117'sine (\%35.5) ilk 12-24 saatte, 57'sine (\%17.3) 24 saat sonrasında yapılmıștır. 84 (\%25.5) hastaya en sık (\%88.1) adrenalin enjeksiyonu olmak üzere endoskopik tedavi uygulanmıștır. Hastaların 122'sine (\%37) üreaz testi yapılmıș, 107'sinde (\%87) Helikobakter pozitif olarak bulunmus. Ilk 12 saatte $0.81 \pm 1.0$, totalde $1.8 \pm 2.1$ eritrosit süspansiyonu verilmiştir. En sık rastlanan kanama nedenleri; 257 'de (\%77.9) peptik ülser, 119'da (\%36.1) mide ülseri, 138'de (\%41.8) duodenal ülser) ve erozif gastrittir ( $n=203$, \%61.5). Rockall skorlamasina göre 61 (\%18.5) hasta düsük risk, 260 (\% 78.8) hasta orta risk ve 9 (\%2.7) hasta yüksek riskliydi. Forrest evrelemesine göre çoğu evre 3 ülsere sahipti ( $n=153$, \%40.9). Evre $2 B$ ülserlerse mortaliteyle pozitif koreleydi. 7 hastaya (\%2.1) cerrahi tedavi gerekti, 6'sında (\%1.8) ölüm gerçeklești. Sonuç: Varis dıșı üst gastrointestinal kanama erkeklerde ve yaşlilarda daha sık görülmekte olup en sık nedeni peptik ülserdir. Yarısından fazlasında nonsteroid anti-inflamatuvar ilaç ve aspirin kullanımı risk faktörü olarak saptandı. Mortalite, cerrahi ve eritrosit süspansiyon replasmanı ihtiyacı oldukça düşük saptandı. Bunun nedeni erken (ilk 24 saat) endoskopik inceleme ve müdahalenin yüksek oranda olmasindan kaynaklanabilir.
\end{abstract}

Anahtar kelimeler: Varis dışı üst gastrointestinal kanama, etyoloji, endoskopi

\section{GİRIŞ}

Varis dışı üst gastrointestinal sistem kanamaları (VDÜGK) gastrointestinal sistemin en sık karşılaşılan acil sağlık problemlerindendir. $\mathrm{H}_{2}$ reseptör antagonistlerin yetmişli yılların ortasında bulunması ve proton pompa inhibitörleri (PPI)'nin seksenli yılların sonunda bulunmasıly ülser komplikasyonlarını önleme, tekrar kanamayı azaltma ve ülser iyileşmesini sağlama olanakları doğmuştur. Ayrıca Helikobakter pylori (Hp) enfeksiyonunun peptik ülser gelişiminde rolü olduğu ve eradikasyonunun ülser kanama tekrarını önlediği görülmüş-
Background and Aims: Non-variceal upper gastrointestinal bleeding (NVUGB) is one of the most frequent emergencies. The aim of the present study was to determine the demographic and clinical features of NVUGB patients. Materials and methods: Patients with NVUGB admitted between 2005-2010 years examined with endoscopy were evaluated retrospectively in terms of demographical characteristics, etiological risk factors, treatment modalities and mortality. Results: Mean age of 228 (\%77) male and 120 (\%23) female was 59, 9 (17-99). 84 (\%25.5) of the patients were smoking, 12 (\%7) were drinking alcohol, 292 (\%88.5) were using drug (148/292 (\%44.8) nonsteroidal anti-inflammatory drug (NSAIID), 113/292 (\%34.2) acetyl salicylic acid. Hypertension (n=96, \%29.1) was the most common comorbidty. Endoscopic procedure time: $156(\% 47.3)$ in first 12 hours, 117 (\%35.5) in first 12-24 hours, and 57 (\%17.3) after 24 hours. Endoscopic therapy was performed in 84 (\%25.5) of the patients. Adrenalin injection was the most frequent treatment modality. Urease test was performed in 122 (\%37) of the patients and $107(\% 87)$ of this was helicobacter pylori positive. Patients were given $0.81 \pm 1.0$ erythrocyte suspension at the first 12 hours, totally $1.8 \pm 2.1$ erythrocyte suspension were given. Conclusion: The most common causes of bleeeding were; 257 (\%77.9) peptic ulcer, 119 (\% 36.1) gastric ulcer, 203 (\%61.5) and erosive gastritis. According to rockall score 61 (\%18.5) patients had low risk, $260(\% 78.8)$ patients had moderate risk and $9(\% 2.7)$ patients had high risk. According to forrest score most of the patients had stage $3 \mathrm{ul}$ cer (n=153,\%40.9) and stage $2 B$ correlated with mortality positivley. Seven (\%2.1) patients required surgical treatment and six (\%1.8) patients died. Peptic ulcer was the most common cause of non-variciel upper gastrointestinal bleeding. Bleeding is seen more commonly in males and elders. Acetyl salicylic acid and NSAIID were found as risk factors in over half of the bleeding patients. Rate of mortality, surgery and transfusion of erythrocyte suspension was very low. This might be related to the high rate of early endoscopy and endoscopical therapy.

Key words: Non-variciel upper gastrointestinal system bleeding, etiology, endoscopy

tür. Endoskopik olanakların kanama nedenini belirlemesi ve tedavi şansını sağlamasına rağmen toplumun yaşlanması daha fazla komorbidite ve ilaç kullanımına yol açtığından halen VDÜGK önemli sağlık problemlerindendir.

Üst gastrointestinal sistem (GIS) kanaması sık olup 100binde 50-150 kişide görülmektedir. Erkeklerde ve yaşlilarda daha sık rastlanmaktadır (1-3). Varis dişı akut üst GIS kanamalar en sık peptik ülsere bağlıdır (4). Bunun dışında anjiyomalar, Mallory Weiss yırtığı, tümörler, erozyonlar, dieulafoy lezyon- 
ları etyolojide yer alır. Endoskopik ve farmakolojik tedavilerdeki ilerlemelere karşın mortalite halen yüksektir (5-7). Bu durum muhtemelen hastaların çoğunluğunun ileri yaşta olması, birlikte başka hastalıkların da bulunması, endoskopik hemostatik tekniklerin kullanımının yaygın olmamasından kaynaklaniyor olabilir (7).

Akut üst GISS kanamalarının tedavisi resüsitasyon, kanama yerinin tespiti, kanamanın durdurulması, kanama tekrarının önlenmesi aşamalarını kapsamaktadır $(8,9)$. Hastalar tekrar kanama ve mortalite riskine göre düşük riskli ve yüksek riskli olarak kategorize edilmelidir. Akut VDÜGK'sında birçok prognostik faktör tespit edilmiştir. Bunlardan bazıları: Şok, melena, başvuruda anemi, rektumda ve gastrik aspiratta anlamlı taze kan, birlikte sepsis, genel sağlık durumunun kötü olması, karaciğer, böbrek, kalp hastalığı, büyük ülser, endoskopik tedaviye rağmen devam eden kanama, tekrar kanama olmasıdır (4). Bunların dışında prognoz değerlendirilmesinin sistematik ve pratik olması amaciyla birkaç adet skorlama sistemi geliştirilmiştir. Bu skorlama sistemlerinden Rockall Risk Skorunun mortalite ve tekrar kanama riski açısından validasyonu yapılmıştır (10).

Yakın zamanda 734 hastanın değerlendirildiği bir çalışmada olguların \%33'ünde kanama nedeni olarak ülser, \%74'ünde ise bir ve birden fazla komorbidite saptanmıştır. Mortalite oranı \%3.9 olarak ve cerrahiye gereksinim \%1.9 olarak bulunmuştur (11). İki dekat önce ve sonrasının karşılaştırıldığı bir çalışmada ülsere bağlı ve 70 yaş altında kanama insidansinda ve mortalite oranında azalma olduğu, non-steroid antiinflamatuvar ilaç (NSAİ) kullanımına bağlı üst GíS kanama insidansında ve ko-morbiditede ise artış olduğu bildirilmiştir (12).

1020 hastayı içeren Italyan çok merkezli çalışmada mortalite oranı \% 4.5 oranında bulunmuş ve bu olguların \%85'inde bir veya birden fazla ko-morbidite saptanmıştır. Otuz günlük tekrar kanama inisiyal endoskopik hemostazda başarısızlık ve ciddi ko-morbidite ile ilişkili bulunmuştur (13). Ko-morbidite ile mortalite arasındaki ilişki diğer çalışmalarda da gösterilmiştir (14, 15).

Varis dışı üst gastrointestinal kanama'nın epidemiyolojisi değişmektedir. Tedavideki gelişmelere bağlı olarak mortalite ve cerrahi gereksiniminin azalması da beklenebilir. Biz bu çalışmada VDÜGK'lı hastalarımızın demografik verilerini, etyolojik nedenlerini, tedavi yöntemlerini, mortalite ve morbidite ile ilişkili faktörleri retrospektif olarak araştırmayı amaçladık.

\section{GEREC VE YÖNTEM}

Çalışmamıza, Fırat Üniversitesi Hastanesi İç Hastalıkları Gastroenteroloji Bilim Dalı Kliniği'nde 2005-2010 yılları arasında yatarak takibe alınan, VDÜGK tanısı konulmuş hastalar alındı. ICD-10 tanı kodundan yararlanarak hasta dosyalarına ulaşıldı.
Hastaların dosyalarından gerekli bilgileri elde etmek amacıyla bir form oluşturuldu. Bu formda; hastalar 18 yaş üstü olup 18-30 yaş, 30-40 yaş, 40-60 yaş ve 60 yaş üstü olarak gruplandırıldı. Her bir gruba ayrı numara verildi. Alkol ve sigara kullanımı araştırıldı. Hastaların komorbiditelerini araştırmak amacıyla hastada bulunan kardiyak hastalıklar, akciğer hastalıkları, tip2 Diabetes Mellitus (DM), hipertansiyon (HT), malignite, böbrek hastalıkları, karaciğer hastalıkları, hematolojik hastalıklar ve serebrovasküler hastalık başta olmak üzere bu gruba girmeyen hastalıklar ayrı olarak gruplandırıldı.

Daha önce üst gastrointestinal kanama öyküsü olup olmadığl, hastaneye hastanın kabul şekli kaydedildi. Hastaların kabul şekli olarak 3 grup oluşturuldu. Bunlar; akut kanama ile başvuran hastalar, başka bir klinikte yatarken kanama gelişen hastalar ve bu iki gruba girmeyen hastalar şeklinde idi.

Hastaların başvuru semptomları hematemez, melena, hematokezya, şok-senkop ve karın ağnısı şeklinde hastaların anamnezleri incelenerek tek tek değerlendirildi.

Hastaların yatışındaki vital bulguları hemşire gözlemleri kullanılarak nabız ve tansiyon değerlerine göre 3 grupta incelendi. Bunlar; 1.grup; Nabızın dakikada 100'ün altında ve sistolik kanbasıncının 100 mmHg'nın üzerinde olduğu normotansif grup. 2.grup; Nabızın dakikada 100'ün üzerinde olduğu taşikardik grup. 3.grup; Sistolik kanbasıncının 100 mmHg'nın altında olduğu hipotansif grup idi.

Hastaların anamnezlerinden kullandığı ilaç olup olmadığı incelendikten sonra, eğer hastaların ilaç kullanımı var ise aspirin, klopidogrel, kumadin, heparin, NSAIII, PPI, oral antidiabetik ve antihipertansiflerin olduğu diğer gruplara girmeyen ilaçlar ayrı ayrı gruplandırıldı.

Kanama sonrası 30 gün içinde veya 30 gün sonrasında tekrar kanama nedeniyle yatarak takibe alınıp alınmadığı kaydedildi.

Hastalar takibe alındıktan sonra yapılan ilk endoskopi zamanı ilk 12 saat, 12-24 saat, 24 saatten sonra olmak üzere 3 grup oluşturuldu. Ayrıca hastalara ilk 5 gün içinde tekrar kanama nedeniyle 2. kez endoskopi yapılıp yapılmadığı, yapıldı ise endoskopik tanısı ve endoskopi esnasinda hemostaz uygulanıp uygulanmadığı incelendi.

$H p$ varlığı için üreaz testi yapılıp yapılmadığına, yapıldı ise sonucuna bakıldı.

Hastaların risk oranını belirlemek amacıyla Rockall Risk Skorlama sistemi kullanıldı. Bu skorlama sisteminde hastaların yaş, vital bulgu, komorbiditeleri ve endoskopik tanıları kullanıldı ve 3 grup oluşturuldu. Bu kriterlere göre toplamda 3'e kadar değer alanlar düşük riskli olup 1.grubu, 3-7 arası değer alanlar orta riskli olup 2.grubu, 8 ve üzeri değer alanlar yüksek riskli olup 3.grubu oluşturdu (10). 
Endoskopik tanı bulguları özofajit, mide ülser, duodenal ülser, eroziv gastrit, eroziv duodenit, portal hipertansif gastropati, malignite, Mallory Weiss yırtığı ve bu gruplara girmeyen diğer tanılar olarak gruplandırıldı. Endoskopide tanısı peptik ülser olan hastalar Forrest evresine göre evrelendi (Tablo 1) ve 5 grup oluşturuldu. Endoskopi esnasinda kanamaya yönelik hemostaz teknikleri kullanılıp kullanılmadığına endoskopi raporundan bakılarak değerlendirildi. Yapılan endoskopik müdahale; skleroterapi, adrenalin injeksiyonu, argon plazma koagülasyon, hemoklip ve diğer olarak gruplandırıldı.

Hastalara uygulanan medikal tedavileri değerlendirmek amacıyla doktor orderları, hemşire gözlemleri incelendi ve tedavide kullanılan ilaçlar PPI, $\mathrm{H}_{2}$ reseptör blokerleri, vasopressin ya da analogları, antibiyotik ve diğer olacak şekilde gruplandırıldı. PPİ kullanan hastalarda, PPI uygulama şekli oral, intravenöz bolus, intravenöz infüzyon şeklinde 3 gruba ayrıldi.

Hastalara ilk 12 saatte ve yattığ sürece verilen toplam kan tranfüzyonu epikriz ve hemşire gözlemi kullanılarak kaydedildi. Hastaların klinikte yattığı sürede VDÜGK nedeniyle cerrahi müdahale yapılıp yapılmadığı epikriz ve konsultasyonlar incelenerek değerlendirildi.

Hastaların VDÜGK nedeniyle klinikte yattığı sürede ölüm gelişip gelişmediği ve ölüm varsa kanamaya mı yoksa kanama dışı nedenlere bağlı olup olmadığı belirtildi. Kanamaya bağlı olan ölümlerde kanamanın kontrol altına alınamamasına bağlı ölüm, endoskopiye bağlı veya cerrahiye bağlı ölüm olacak şekilde gruplandırıldı. Kanama dışı ölüm nedenleri ise kardiyak, pulmoner, serebrovasküler nedenler, terminal malignite ve multiorgan yetmezliğine bağlı ölümler şeklinde gruplandırildi.

Istatistiksel analizler ve grafikler SPSS 12.0 ve microsoft office 2003 excel programları kullanılarak yapıldı. Elde edilen veriler Statistical Package for the Social Sciences (SPSS 10.0, Chicago, IL, USA) programına yüklendi. Çalışmada, sonuçlar ortalama \pm standart sapma olarak gösterildi. Korelasyon analizleri, Spearman testi ile yapıldı, $\mathrm{p}<0.05$ değerler istatistiksel olarak anlamlı kabul edildi.

\section{BULGULAR}

\section{Hastaların Klinik ve Demografik Özellikleri}

330 hastanın 102'si (\%30.9) kadın, 228'i (\%69.1) erkekti. Yaş ortalaması $59.91 \pm 7.5$ (17-99) idi. Kadın hastaların yaş ortalaması 59.5 \pm 19.9 , erkek hastaların yaş ortalaması $60.1 \pm 16,2$ olarak saptandı ( $p>0.05)$. Hastaların yaş gruplarına göre dağılımı Şekil 1'de gösterilmiştir.

Yaş artışı ile daha önce geçirilmiş GİS kanama öyküsü ve duodenal ülser arasında negatif Rockall Skoru, NSAII kullanımı ve Mallory Weiss ile de pozitif korelasyon vardı $(\mathrm{p}<0.05)$.
Risk faktörleri: Hastaların 246 (\% 74.5) tanesi sigara içmiyordu, 84 (\%25.5) hasta ise sigara kullaniyordu. Alkol kullanan sadece 12 (\%3.6) hasta vard. Eroziv duodenit hem alkol kullanımı hem de sigara içmeyle pozitif koreleydi ( $\mathrm{p}<0.05)$. Ayrıca sigara içenlere beş gün içinde tekrar endoskopi yapılması arasında korelasyon vardı $(\mathrm{r}=0.173, \mathrm{p}<0.01)$. En sık eşlik eden hastalık HT 96 (\%29.1) idi. Kardiyovasküler (KV) hastalığı olanların 13'ünde (\%17.8) DM, 3l'inde ise (\%42.5) HT var idi. Varis dışı üst GIS kanamalı hastalara eşlik eden hastalıklar Şekil 2'de gösterilmiştir.

Hastaların 292'sinde (\%88.5) ilaç kullanım öyküsü vardı. En sık olarak 148 (\%44.8) hasta ile NSAII kullanımı vardı. İlaç kullanımı Şekil 3’te gösterilmiştir.

Tablo 1. Endoskopik özelliklere göre Forrest sınıflaması
\begin{tabular}{lc} 
(8). & Forrest evresi \\
\hline Endoskopik özellikler & I (A\&B) \\
\hline Aktif kanama & IIA \\
\hline Kanamayan görünen damar & IIB \\
Yapıșı pıhtı & IIC \\
Mukoza aynı yükseklikte kan lekesi & III \\
\hline Temiz ülser zemini & \\
\hline
\end{tabular}

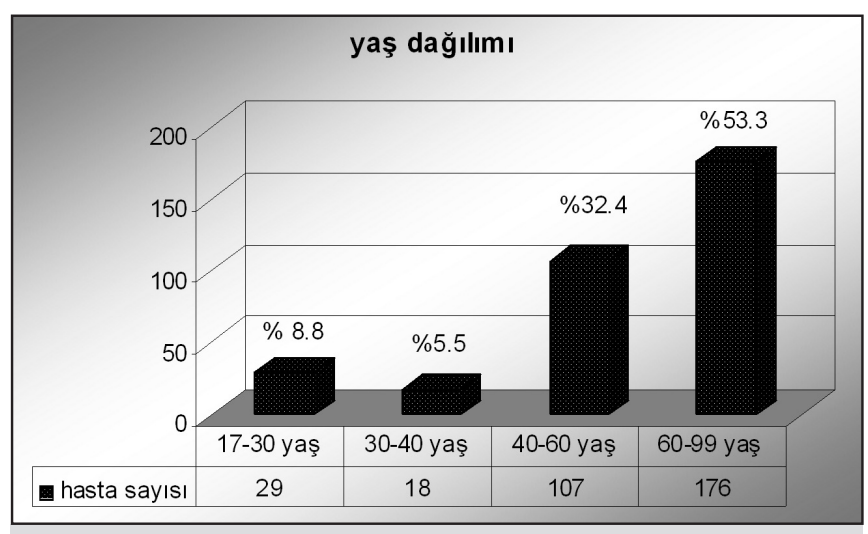

Şekil 1. Hastaların yaş dağılımı.

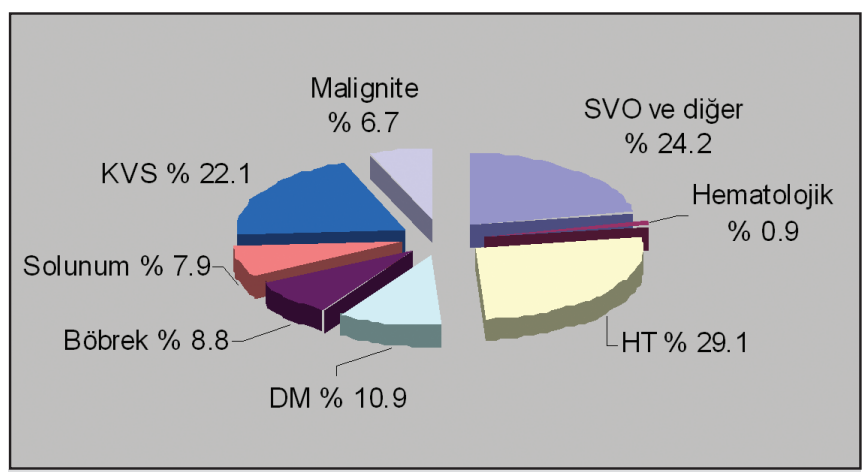

Şekil 2. Hastaların kronik hastalıkları. 


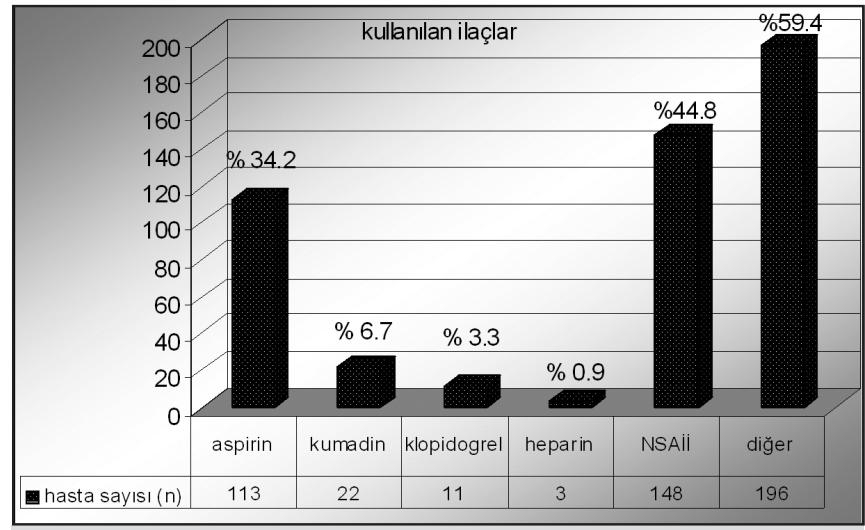

Şekil 3. Hastaların önceden kullandığı ilaçlar.

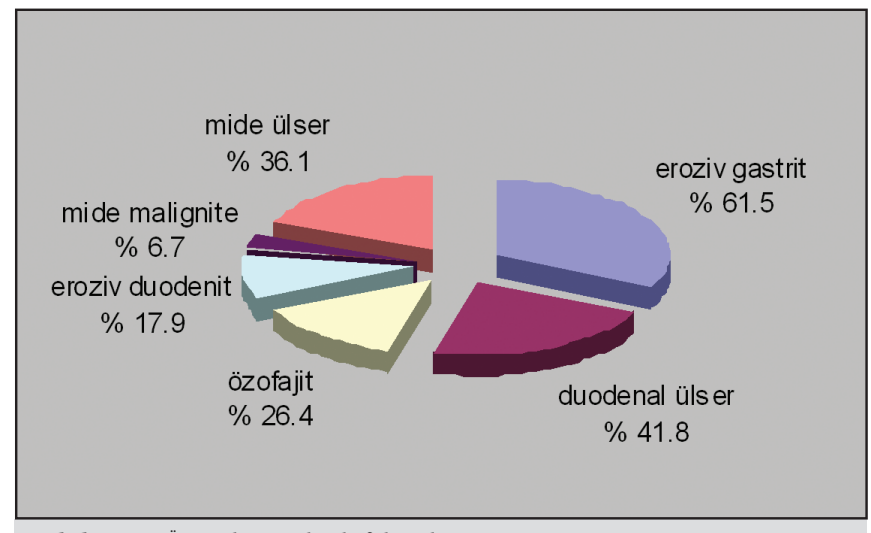

Şekil 4. VDÜGK'da etyolojik faktörler.

Hastaların 122 (\%37) tanesine Hp testi yapılmıs ve 107 (\%87) hastada pozitif bulunmuş. DM'u olan hastalarda $H p$ pozitifliği anlamlı olarak düşüktü $(\mathrm{p}<0.05)$. Ayrıca $H p$ testi pozitif çıkan hastaların endoskopik tanılarında eroziv gastrit anlamlı olarak düşüktü $(\mathrm{p}<0.05)$.

Etyoloji: Endoskopik incelemeye göre en sık neden peptik ülser (n=257, (\%77.9)) olup bunların 119'unda (\%36.1) mide ülseri, 138'inde (\%41.8) duodenal ülser tespit edildi. Etyolojik faktörler Şekil 4’te gösterilmiştir. En sık Forrest evre 3 $(\mathrm{n}=135, \% 40.9)$ ülser saptand. Forrest evrelemesine göre gruplar Şekil 5'de, Forrest evrelemesine göre bulgular Tablo 2'de gösterilmiştir.

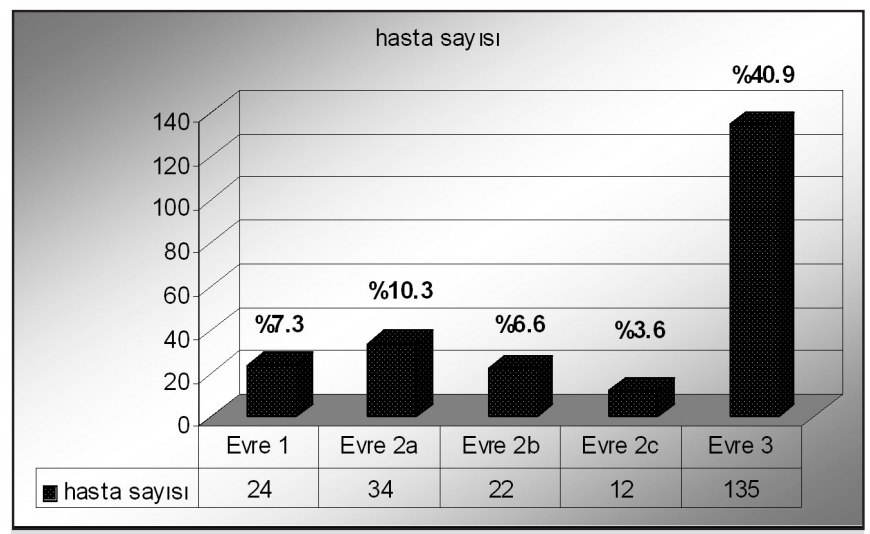

Şekil 5. Forrest evrelemesi.

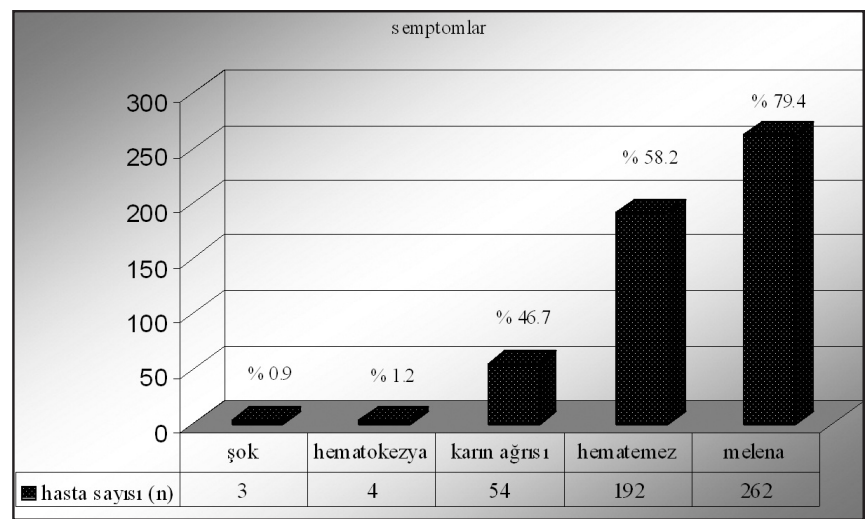

Şekil 6. Hastaların geliş semptomlanı.

Forrest evre 3 ülser; endoskopik müdahale, mortalite, vital bulgular ve Rockall Skoru $(\mathrm{p}<0.01)$ ile negatif, endoskopi yapilma zamanı ile pozitif koreleydi $(\mathrm{p}<0.001)$. Forrest evre $2 B$ ülser ile şok, mortalite ve Rockall Skor şiddeti, Forrest evre 1 ülser ile kardiyak hastalık ve kumadin kullanımı arasında pozitif ilişki saptandı $(\mathrm{p}<0.05)$. Endoskopik müdahale ile Forrest evre 2C, 2B, 2A ve evre 1 ülser pozitif koreleydi (hepsinde $\mathrm{p}<0.05)$.

Başvuru semptomları Şekil 6'da gösterilmiştir. Hematemez; kadın cinsiyet ve NSAit kullanımı ile pozitif, ilk 12 saat içinde verilen eritrosit süspansiyonu (ES) desteği, totalde verilen ES desteği ve endoskopi yapılma zamanı ile negatif koreleydi

Tablo 2. Forrest evrelemesine göre bulgular

$\begin{array}{lccccc}\begin{array}{l}\text { Forrest evresi } \\ (\mathbf{n}=227)\end{array} & \begin{array}{c}\text { Hematemez } \\ (\mathbf{n}=192)\end{array} & \begin{array}{c}\text { Melena } \\ (\mathbf{n}=262)\end{array} & \begin{array}{c}\text { Tekrar endoskopi } \\ (\mathbf{n}=15)\end{array} & \begin{array}{c}\text { Aspirin } \\ (\mathbf{n}=113)\end{array} & \begin{array}{c}\text { NSAII } \\ (\mathbf{n}=\mathbf{1 4 8})\end{array} \\ \text { I (24) } & 17 / 192 & 18 / 262 & 4 / 15 & 7 / 113 & 9 / 148 \\ \text { IIA (34) } & 25 / 192 & 29 / 262 & 2 / 15 & 13 / 113 & 14 / 148 \\ \text { IIB (22) } & 14 / 192 & 19 / 262 & 2 / 15 & 6 / 113 & 13 / 148 \\ \text { IIC (12) } & 5 / 192 & 10 / 262 & 2 / 15 & 4 / 113 & 6 / 148 \\ \text { III (135) } & 69 / 192 & 114 / 262 & 1 / 15 & 52 / 113 & 60 / 148\end{array}$


(hepsinde $\mathrm{p}<0.05$ ). Melenayla; erkek cinsiyet, aspirin kullanımi, duodenal ülser, ilk 12 saatte ve totalde verilen ES desteği arasinda pozitif, Mallory Weiss ile negatif korelasyon tespit edildi (hepsinde $\mathrm{p}<0.05$ ).

Vital bulgulara bakıldığında 163 (\%49.4) hastada nabız 100'den az ve sistolik kan basinc1 100 mmHg'nın üzerinde, 67 (\%20.3) hasta taşikardik, 100 (\%30.3) hastanın ise sistolik kan basıncı 100 mmHg'nın altında idi.

Rockall Risk Skorlamasına göre düşük, orta ve yüksek risk grubu olarak sinıflandırıldı. Hastaların 61 (\%18.5) tanesi düşük risk gurubunda, 260 (\%78.8) hasta orta risk grubunda ve 9 (\%2.7) hasta ise yüksek risk grubunda idi.

Endoskopi yapılma zamanı ile Rockall Skor şiddeti arasında negatif, endoskopik müdahale yapılması, ilk 12 saatte ve totalde verilen ES desteği ile pozitif korelasyon saptandı (p hepsinde $<0.05)$.

\section{Tanı ve Tedavi}

Hastalarin 156 tanesine (\%47.3) ilk 12 saatte, 117 tanesine (\%35.5) 12-24 saatte, 57 hastaya ise (\%17.3) 24 saatten sonra üst GIS endoskopi yapılmış. İlk 24 saatte ise toplamda 273 (\%82.8) hastaya endoskopi yapılmış. Forrest evre 3 ülseri olan hastalara endoskopi geç yapılırken, evre 2C, evre 2A, evre 1 ülseri olan hastalara endoskopinin erken yapılmış olduğu saptandı ( $\mathrm{p}<0.05)$. Erken endoskopi yapılması ile endoskopik müdahale ihtiyacı koreleydi $(\mathrm{p}<0.001)$. Ayrıca endoskopi zamanı ile cerrahi müdahale, ilk 12 saatte ve totalde verilen ES desteği arasında negatif korelasyon saptandı. Yani erken endoskopi yapılanlarda cerrahi müdahale ve ES ihtiyacı fazla idi.

15 hastaya (\%4.5) tekrar endoskopi yapılmış ve bunların 3’üne (\%0.9) tekrar endoskopik müdahale edilmişti. Tekrar endoskopi yapılan 15 hastanın 6 tanesinde (\%37.5) mide ülseri, 5 tanesinde ise (\% 31.3) duodenal ülser tespit edildi.

Endoskopik tedavi 84 (\%25.5) hastada yapılmış. Bunların; 74'ünde (\%88.1) adrenalin ile skleroterapi, 28'inde (\%28.5) argon plazma, l'de (\%1.1) hemoklip, 8'inde ise (\%9.5) bunların dışındaki yöntemler kullanılmış.

Tüm hastaların tedavisinde PPİ kullanılmış. Fakat hastalara PPI uygulama şekilleri farklılık göstermiş. 8 hastaya (\%2.4) oral, 27 hastaya (\%8.2) intravenöz (IV) bolus, 295 hastaya ise $(\% 89,4)$ IV infüzyon şeklinde uygulanmış.

Hastaların 174 (\%52.7) tanesine ilk 12 saatte hiç ES verilmemiş. 71 (\%21.5) tanesine 1 ünite, 65 (\%19.7) tanesine 2 ünite, 14 (\%4.2) tanesine 3 ünite, 5 (\%1.5) tanesine 4 ünite, 1 tanesine ise 5 ünite ES ilk 12 saatte verilmiş. Hastalara ilk 12 saatte verilen ES ortalaması $0.81 \pm 1.0$ idi, yattığı sürece verilen ES ortalaması ise $1.8 \pm 2.1$ (0-11 ünite) idi.
Hastaların 5 tanesi (\%1.5) otuzgün içinde, 7 tanesi (\%2.1) otuz gün sonrasında VDÜGK nedeniyle tekrar kliniğimizde takibe alınmış idi. 323 hasta (\%97.9) akut VDÜGK nedeniyle hastanemize başvurmuş, 7 (\%2.1) hasta ise diğer kliniklerde takipte iken VDÜGK gelişmesi üzerine kliniğimize devir alınmiş.

Hastaların 58'inde (\%17.6) daha önceden VDÜGK öyküsü olduğu tespit edildi. Bunların 18'inin (\%31) aspirin, 25 tanesi (\%43.1) NSAII kullandığı görüldü. 19'unda Hp testi yapılmış ve 16'sında (\%84.2) pozitif saptanmış, 26'da (\%44.8) duodenal ülser, 22'de (\%37.9) mide ülser, 13'de (\%22.4) özofajit, 13'de (\%22.4) eroziv duodenit, 32'de (\%55.2) eroziv gastrit, 4'de (\%6.9) mide malignitesi, l'de (\%1.7) Mallory Weiss lezyonu tespit edildi. Bu değerler çalışmaya alınan tüm hastaların epidemiyolojik yüzdelerine benzerdi.

Hastaların 7'sine (\%2.1) kanama nedeniyle cerrahi müdahale yapıldı. Cerrahi müdahale yapılan hastaların özellikleri incelendiğinde; bu hastalarda hematokezya, mide malignitesi, dieulafoy lezyonları ve ilk 12 saatte ve totalde verilen ES desteği ile pozitif korelasyon saptandı $(\mathrm{p}<0.05)$.

Altı hastada (\%1.8) ölüm gerçekleşti. Bunların 4 (\%1.2) tanesi kanamaya bağlı, 2 (\%0.6) tanesi ise kanama dışı nedenlere bağlı idi. Özellikleri incelendiğinde mortalite ile karın ağrısı, şok ve Forrest evre 2B ülserle pozitif, Forrest evre 3 ülser ile negatif korelasyon vardı (hepsinde p<0.05). 1 tanesi 40-60 yaş aralığında, 5 tanesi ise 60 yaş üstündeydi. 1'i (\%16.6) kadın 5’i (\%83.3) erkekti. Rockall skoruna bakıldığında yarısı orta risk, yarısı yüksek risk grubundaydı. Hepsi akut GIS kanama ile acil servisten takibe alınan hastalardı. Bu hastaların 5'ine (\%83.3) ilk 12 saatte, l'ine (\%16.6) ise 12-24 saatte endoskopi yapılmıs, 2'sine endoskopi sırasında adrenalin injeksiyonu yapılmıştı. Endoskopilerinde peptik ülser tespit edilen 4 vakanın 3'ü duodenal ülserdi, bu 4 vakanın 2'si Forrest evre $2 \mathrm{~A}, 2$ 'si ise forrest evre $2 \mathrm{~B}$ olarak tespit edildi.

\section{TARTISSMA}

VDÜGK insidansı yaşla birlikte anlamlı artış göstermektedir (16-19). Ülkemizde İzmir bölgesinde yapılan bir çalışmada 412 VDÜGK olgusunun yaş ortalaması 62 olup, \%75'ini erkek hastalar oluşturmuştur (19). VDÜGK erkeklerde anlamlı olarak yüksektir $(1,17,20,21)$. Bizim çalışmamızda da hastaların yarısından fazlası (\%53.3) 60 yaş üstünde olup, erkek cinsiyet fazlaydı. Ancak duodenal ülser ve daha önceden geçirilmiş üst GİS kanama öyküsü gençlerde daha sıktı.

Varis dişı üst gastrointestinal kanama en sık peptik ülsere bağlıdır (4). Özofajit ve eroziv gastro/duodenit VDÜGK'nın ikinci sırada nedeni olup hastaların \%16-20'sinde ise birden fazla tanı bildirilmiştir $(20,22)$. Biz en sık sebep olarak peptik ülseri saptadık. Fakat duodenal ülser tek başına ele alındığında en sık kanama nedeni değildi. Çünkü eroziv gastrit du- 
odenal ülser kanamalarından daha fazlaydı. Bunun sebebi ilaç kullanımının ve beslenme alışkanlıklarının değişmesi olabilir. Ayrıca endoskopik tanı yöntemlerinin gelişmesiyle ve endoskopi yapan kişilerinin tecrübesinin artmasıyla eroziv lezyonların gözden kaçırılmayıp daha fazla tespit edilmesinden olabilir.

Yunanistanda yapılan bir çalışmada 1986-1987 yılları ile 2000-2001 yılları retrospektif olarak üst GİS kanamalar açısindan incelenmiştir (23). 2000-2001 yılları arasındaki hastalar anlamlı olarak yaşlı, komorbid hastalığa sahip, NSAID veya aspirin kullanımı daha fazla saptanmıştır. Özen ve ark. (19) yaptığı çalışmada olguların \%51.2'sinde ek hastalık olduğunu, en sık olarak aterosklerotik kalp hastalığı, DM ve HT bulunduğunu bildirmiştir. Bizim çalışmamızda da bir ve birden fazla kronik hastalık ve NSAID kullanımı fazlaydı. Komorbid hastalıklar Rockall Skor şiddeti ile pozitif koreleydi.

Non steroid anti-inflamatuvar ilaç kullanımı ve Hp enfeksiyonunun bağımsız ve anlamlı olarak peptik ülser hastalığını ve peptik ülser kanamalarını arttırdığı görülmüştür $(24,25)$. Bir meta-analiz çalışmasında NSAII kullanımı peptik ülser kanamalarinda kontrol grubuna göre anlaml olarak daha fazla iken, Hp enfeksiyonunun da sadece marjinal olarak ülser kanamaları riskinde artışa yol açtığı görülmüştür (24). Tüm NSAII kullananlarda her yıl \%1-2 peptik ülser kanaması gibi komplikasyon gelişmektedir $(26,27)$. Üst gastrointestinal kanamalı hastalar arasında NSAII kullanımı Fransa'da \%29 iken, Yunanistanda \%60'ın üzerindedir $(23,28)$. Almanya'da yapılan son çalışmalarda peptik ülser kanamalı hastalarda 1999-2000 yıllarında NSAII kullanımı 1989-1990 yıllarına göre daha yüksek bulunmuştur (\%45’e \%27) (18). Son dekatta ise dejeneratif eklem hastalığı nedeniyle NSAlI'ların düzenli olarak alındığı görülmüştür (29). Trombotik kardiyovasküler ve periferal kardiyovasküler hastalığı azalttığından kullanımı artan aspirinde son iki dekatta peptik ülser hastalığının ve ilişkili komplikasyonlarının önemli bir nedenidir (29, 30). Bunların dışında birçok ilaç kullanımı ile ülser komplikasyonlarını dramatik bir biçimde artırmıştır (31). Bizim çalışmamızda da diğer çalışmalarda olduğu gibi ilaç kullanımı en fazla NSAII (\%44.8) ve aspirin (\%34.2) olmak üzere yüksekti (\%88.5). Diğer çalışmalar daha çok peptik ülser kanamalı hastalarda yapılmıştı, fakat bu çalışma göstermiş ki VDÜGK nedenlerinin hepsinde NSAII ve aspirin bassta olmak üzere ilaç kullanımı önemli bir yere sahiptir.

Sigara içimi ülser rekürrensini ve yavaş iyileşme riskini artırır (31). Bizim çalışmamızda sigara kullanım hikayesi \%25 olup, sigara içen hastalarda 5 gün içinde tekrar endoskopi yapılması anlamlı olarak yüksekti. Sigara yavaş iyileşme ve rekurrense yol açarak endoskopik hemostazın yapılmasında zorluk oluşturup tekrar endoskopi ihtiyacı doğurmaktadır.

Dünyada 1 milyon insan Hp enfeksiyonu ile enfekte olup, ge- lişmiş ülkelerde prevalansı yüksektir $(32,33)$. Peptik ülser kanamalı hastalarda $H p$ eradikasyonu tekrar kanama riskini azaltır $(34,35)$. Yapılan geniş bir kohort çalışmada peptik ülser kanamalı hastalara hastanede yattığı sürede \%47'sine $H p$ için test yapılmış ve bunların \%45'inde $H p$ pozitif bulunmuştur. Almanyada yapılan bir çalışmada peptik ülser kanamalı hastaların \%56'sinda (18), Hollanda da test yapilan \%65 hastanın \%43'ünde $H p$ pozitif bulunmuştur (22). Bizim çalışmamızda ise 122 hastaya (\%37) Hp testi yapılmış ve 107 hastada (\%87) pozitif bulunmuş. Bu yüksekliğin olası sebebi ülkemizde Hp enfeksiyonunun yaygınlığı ve yeterince eradike edilememesindendir. Fakat açıkca görülmektedir ki VDÜGK hastalarında $H p$ belirgin olarak yüksektir ve VDÜGK önlenmesi için uygun eradikasyon tedavisi verilmelidir.

Farklı toplumlarda yapılan çalışmalara göre VDÜGK hastalarinda mortalite \%3-14 arasindadır (36). Kanada'da bu oran \%3.5-5.5'dır $(37,38)$. Ülkemizde ise mortalite \%2 dolaylarında düşük olarak bildirilmiştir $(19,39)$. Bizim çalışmamızda da mortalite düşük (\%1.8) olup bunların \%1.2'si kanamaya bağlıyken \%0.6'sı kanama dışı nedenlere bağlıydı. Bu sonuç ülkemizde yapılan diğer iki çalışmadakine benzer, diğer ülkelerde yapılan çalışmalara göre düşüktü. Bunun sebebi ülkemizde yapılan diğer iki çalışma ve bizim çalışmamız daha yakın zamanı incelediğinden gelişen endoskopik ve medikal tedavi olanakları, endoskopik müdahalenin erken yapılmasının hemostaz sağlamasındaki öneminin görülmesi mortalitenin düşmesine neden olmuş olabilir. Mortalite olanlarda Rockall skoru orta ve yüksek risk grubundaydl. Bu da Rockall skorlamasının önemini ve skor şiddeti fazla olan hastaların hemodinamilerinin erken stabilitesinin sağlanması ve bu hastalara yoğun bakım tedavisinin tercih edilmesi gerektiğini gösterdi.

Mortalitenin dışında ilk 12 saatte ortalama $0.81 \pm 1.0$ ünite, toplamda ise ortalama 1.8 \pm 2.1 ünite ES verilmiştir. Hastaların \%52.7'ne ilk 12 saatte hiç ES verilmemiştir. İstanbulda yapılan bir çalışmada VDÜGK hastalarının \% 74'üne ES verilmiş yani hastaların sadece \%25.9'na ES verilmemiş ve totalde verilen ES ortalaması 2.59 \pm 2.7 tespit edilmiştir (40). Bizim çalışmamızda ise ES ihtiyacı erken yapılan endoskopi ile hemostazın erken sağlanmasından dolayı daha düşüktür.

Mortalitenin azalmasında da en önemli etken endoskopik müdahalenin erken yapılmasıdır. Çünkü yapılan çeşitli gözlemler ve randomize kontrollü çalışmalar erken endoskopinin hastanede kalma ve tranfüzyon ihtiyacını azalttığını göstermiştir. İdeal endoskopinin üst gastrointestinal kanama semptomu olan hastalara mümkün olan en kısa zamanda yapılması gerektiği (ideali ilk 24 saatte) ve bunun da düşük riskli hastalara erken taburcu edilme imkânı verdiği, yüksek riskli hastaların ise yakın takibe alınmasını sağladığı gösterilmiştir (3, 41). Yüksek riskli hastalarda endoskopik hemostazın sağlanması tekrar kanama riskini, ameliyat ihtiyacını ve mortaliteyi azaltır (7). Bizim çalışmamızda hastaların yaklaşık yarısına 
(\%47.3) ilk 12 saatte olacak şekilde \%82'ne 24 saat içinde üst GIS endoskopi yapılmıştır. Erken endoskopi yapılan hastaların özellikleri incelendiğinde Rockall Skor şiddeti yüksek, endoskopik müdahale veya cerrahi müdahale gerektiren, ES replasman ihiyacı olan hastalardı. Ayrıca endoskopi yapılma zamanı ile Forrest evrelemesi birlikte ele alındığında Forrest evre 3 ülseri olan hastalara endoskopinin anlamlı olarak geç yapıldığı, Forrest evre 2C, Forrest evre 2A, Forrest evre 1 ülseri olan hastalarda endoskopinin anlamlı olarak erken yapildığı tespit edildi. Erken endoskopi yapılan hastaların doğru seçimi erken hemostazı sağlayıp mortalitenin azalmasında etkili olmuş olabilir.

Endoskopik tedaviye rağman tekrar kanama \%7-16 iken, peptik ülserin tekrar kanama oranı \%20-22 arasında bulunmuştur $(16,21)$. Bizim çalışmada ise hastaların \%17.6'sında daha önceden VDÜGK öyküsü tespit edildi ve bu oran da yaklaşık, çalışmalardaki tekrar kanama oranına benzerdi. Onbeş (\%4.5) hastaya tekrar endoskopi gerekmiş ve bunların 3'üne de (\%0.9) endoskopik müdahale yapılmıştır.

Hastaların prognozunu ve tekrar kanama riskini belirlemede Rockall Risk skorlaması ve Forest evrelemesi kullanıldı. Rockall skorlaması yaş, ko-morbitedeler, şok durumu ve endoskopik bulgulara dayalıdır. (5). Klinik Rocall Skoru hastaların hemodinamik durumu ve varolan hastalıklarını kapsar. Böylelikle düşük riskli hastaların acil endoskopi ihtiyacının azalabileceğini göstermiştir (42). Bizim çalışmamızda hastaların büyük bir kısmı (\%78.8) orta risk grubunda idi. Bunun nedeni Rockall Skorlama sisteminde orta risk grubu daha geniş bir aralık grubu olduğundan, bu aralıkta olan hasta sayısı fazladır. Sonuçta orta risk grubundaki hastaların da takibi ve tedavisinde yüksek riskli hastalar gibi dikkat etmek gerektiği görüldü. Nitekim ölen hastaların yarısı, cerrahiye alınan 7 hastanın hepsi Rockall Skorlamasina göre orta risk grubundaydi. Ayrica Rockall Skor şiddeti ile hastalarda ilk 12 saatte ve totalde verilen ES desteği anlamlı bir ilişki saptandı. Ölen has- taların diğer yarısı da yüksek risk grubunda idi. Rockall Skorlamasına göre orta ve yüksek grupta olan hastaların mortalite, cerrahi gereksinim, endoskopik müdahale ve kan replasman ihtiyacı yüksektir.

Kanayan ülserin endoskopik görünümüne göre yapılan Forrest evrelemesinde yüksek riske sahip olanlar; evre 1, evre 2A, evre 2B'dir. Düşük riske sahip olanlar ise evre $2 \mathrm{C}$ ve evre 3'dür (5). Bizim çalışmamızda ise forrest evre 2B ülseri olan hastalarda Rockall Skor şiddeti yüksek, Forrest evre 3 ülseri olan hastalarda Rockall skor şiddeti düşüktü.

Forrest evre 2B ülserin son dönem tedavisi tartışmalıdır. Jensen ve ark.'nın (43) yaptığı, ayrıca Bleau ve ark.'nın (44) yaptığı iki ayrı kontrollü randomize çalışmada Forrest evre 2B ülser tabanından yapışı pıhtının kaldırılıp, endoskopik tedavi yapılması gerektiğini savunmuşlardır. Fakat bir başka çalışma göstermiş ki tek başına yüksek doz PPI tedavisi yapışık pihtıyı stabilize edip, kanama riskini düşürmüş ve endoskopik tedaviye gerek kalmamıştır. Fakat forrest evre 2B ülserin büyüklüğü, kronisitesi, mide küçük kurvaturda veya posterior duodenal bulbusda lokalize olmasının önemli olduğu görülmüştür. Bizim çalışmamızda da Forrest evre 2B ülseri olan hastalarla şok ve ölüm arasında pozitif korelasyon saptandı. Bu da bize bu ülserlerin mutlaka tedavisinin yapılması gerektiğini göstermiştir.

Bu çalışma, bize VDÜGK'ların gelişen tedavi tekniklerine rağmen toplumda halen önemli bir sağlık sorunu olduğunu, bunda artan NSAII ve aspirin bezeri ilaç kullanımının, yeterli tedavi edilmeyen $H p$ enfeksiyonunun, yaşla birlikte artan ek hastalıkların olması sayılabilir. Ayrıca bu çalışma erken yapılan endoskopinin mortaliteyi, cerrahiyi ve ES ihtiyacını azalttığını gösterdi. Bu nedenle VDÜGK'lı hastalarda özellikle Forrest evre 2B ülseri olan hastalarda, endoskopi başta olacak şekilde hem tedavi tekniklerinin geliştirilmesi, hem de epidemiyolojisinde yer alan faktörlerle mücadele edilmesine yönelik daha fazla çalışmaya gerek vardır.

\section{KAYNAKLAR}

1. Longstreth GF. Epidemiology of hospitalization for acute upper gastrointestinal hemorrhage: a population-based study. Am J Gastroenterol 1995; 90: 206-210.

2. Gilbert DA. Epidemiology of upper gastrointetinal bleeding. Gastrointest Endosc 1990;36(5 Suppl):S8-13

3. Longstreth GF, Feitelberg SP. Outpatient care of selected patients with acute non-variceal upper gastrointestinal haemorrhage. Lancet 1995;345:108-11.

4. Ferguson CB, Mitchell RM. Nonvariceal upper gastrointestinal bleeding: standard and new treatment. Gastroenterol Clin North Am 2005;34: 607-21.

5. Laine L, Peterson WL. Bleeding peptic ulcer. N Engl J Med 1994;331: 717-27.

6. Hunt PS, Hansky J, Korman MG. Mortality in patients with haematemesis and melaena: a prospective study. Br Med J 1979; 1: 1238-1240.

7. Barkun A, Bardou M, Marshall JK. Nonvariceal Upper GI Bleeding Consensus Conference Group. Consensus recommendations for managing patients with nonvariceal upper gastrointestinal bleeding. Ann Intern Med 2003;139:843-57.

8. Julapalli VR, Graham DY. Appropriate use of intravenous proton pump inhibitors in the management of bleeding peptic ulcer. Dig Dis Sci 2005; 50:1185-93.

9. Consensus statement on therapeutic endoscopy and bleeding ulcers. Consensus Development Panel. Gastrointest Endosc 1990;36(5 Suppl): S62-5.

10. Rockall TA, Logan RF, Devlin HB, Northfield TC. Incidence of and mortality from acute upper gastrointestinal haemorrhage in the United Kingdom. Steering Committee and members of the National Audit of Acute Upper Gastrointestinal Haemorrhage. BMJ 1995;311:222-6. 
11. Halland M, Young M, Fitzgerald MN, et al. Characteristics and outcomes of upper gastrointestinal hemorrhage in a Tertiary Referral Hospital. Dig Dis Sci 2010;55:3430-5

12. Loperfido S, Baldo V, Piovesana E, et al. Changing trends in acute upper-GI bleeding: a population-based study. Gastrointest Endosc 2009;70:212-24.

13. Kapsoritakis AN, Ntounas EA, Makrigiannis EA, et al. Acute upper gastrointestinal bleeding in central Greece: the role of clinical and endoscopic variables in bleeding outcome. Dig Dis Sci 2009;54:333-41.

14. Theocharis GJ, Arvaniti V, Assimakopoulos SF, et al. Acute upper gastrointestinal bleeding in octogenarians: clinical outcome and factors related to mortality. World J Gastroenterol 2008;14:4047-53.

15. Rahme E, Barkun A, Nedjar H, et al. Hospitalizations for upper and lower GI events associated with traditional NSAIDs and acetaminophen among the elderly in Quebec, Canada. Am J Gastroenterol 2008;103: 872-82.

16. Van Leerdam ME, Vreeburg EM, Rauws EA, et al. Acute upper GI bleeding: did anything change? Time trend analysis of incidence and outcome of acute upper GI bleeding between 1993/1994 and 2000. Am J Gastroenterol 2003;98:1494-9.

17. Paspatis GA, Matrella E, Kapsoritakis A, et al. An epidemiological study of acute upper gastrointestinal bleeding in Crete, Greece. Eur J Gastroenterol Hepatol 2000;12:1215-20.

18. Ohmann C, Imhof M, Ruppert C, et al. Timetrends in the epidemiology of peptic ulcer bleeding. Scand J Gastroenterol 2005;40:914-20.

19. Özen E, Tekin F, Oruç N, Özütemiz Ö, et al. Varis dışı üst gastrointestinal kanamal 412 olgunun irdelenmesi. Akademik Gastroenteroloji Dergisi 2007;6:62-7.

20. Blatchford O, Davidson LA, Murray WR, et al. Acute upper gastrointestinal haemorrhage in west of Scotland: case ascertainment study. BMJ 1997;315:510-4.

21. Yavorski RT, Wong RK, Maydonovitch C, et al. Analysis of 3, 294 cases of upper gastrointestinal bleeding in military medical facilities. Am J Gastroenterol 1995;90:568-73.

22. Ramsoekh D, van Leerdam ME, Rauws EA, Tytgat GN. Outcome of peptic ulcer bleeding, nonsteroidal anti-inflammatory drug use, and Helicobacter pylori infection. Clin Gastroenterol Hepatol 2005;3:859-64.

23. Thomopoulos KC, Vagenas KA, Vagianos CE, et al. Changes in aetiology and clinical outcome of acute upper gastrointestinal bleeding during the last 15 years. Eur J Gastroenterol Hepatol 2004;16:177-82.

24. Huang JQ, Sridhar S, Hunt RH. Role of Helicobacter pylori infection and non-steroidal anti-inflammatory drugs in peptic-ulcer disease: a metaanalysis. Lancet 2002;359:14-22.

25. Chan FK, To KF, Wu JC, et al. Eradication of Helicobacter pylori and risk of peptic ulcers in patients starting long-term treatment with nonsteroidal anti-inflammatory drugs: a randomised trial. Lancet 2002;359: 9-13.

26. Wolfe MM, Lichtenstein DR, Singh G. Gastrointestinal toxicity of nonsteroidal antiinflammatory drugs. N Engl J Med 1999;340:1888-99.

27. Silverstein FE, Graham DY, Senior JR, et al. Misoprostol reduces serious gastrointestinal complications in patients with rheumatoid arthritis receiving nonsteroidal anti-inflammatory drugs. Ann Intern Med 1995; 123:241-9.
28. Czernichow P, Hochain P, Nousbaum JB, et al. Epidemiology and course of acute upper gastro-intestinal haemorrhage in four French geographical areas. Eur J Gastroenterol Hepatol 2000;12:175-81.

29. Jyotheeswaran S, Shah AN, Jin HO, et al. Prevalence of Helicobacter pylori in peptic ulcer patients in greater Rochester, NY: is empirical triple therapy justified? Am J Gastroenterol 1998;93:574-8.

30. García Rodríguez LA, Hernández-Díaz S, de Abajo FJ. Association between aspirin and upper gastrointestinal complications: systematic review of epidemiologic studies. Br J Clin Pharmacol 2001;52:563-71.

31. Padussis JC, Pappas TN. Management of bleeding peptic ulcer. Pryor AD, Pappas TN, Branch MS (editors). Gastrointestinal Bleeding. Springer Science Business Media, 2010: 39-64.

32. Arroyo MT, Forne M, de Argila CM, et al. The prevalence of peptic ulcer not related to Helicobacter pylori or non-steroidal anti-inflammatory drug use is negligible in southern Europe. Helicobacter 2004;9:249-54.

33. Nishikawa K, Sugiyama T, Kato M, et al. Non-Helicobacter pylori and non-NSAID peptic ulcer disease in the Japanese population. Eur J Gastroenterol Hepatol 2000;12:635-40.

34. Graham DY, Hepps KS, Ramirez FC, et al. Treatment of Helicobacter pylori reduces the rate of rebleeding in peptic ulcer disease. Scand J Gastroenterol 1993;28:939-42.

35. Lai KC, Hui WM, Wong WM, et al. Treatment of Helicobacter pylori in patients with duodenal ulcer hemorrhage a long-term randomized, controlled study. Am J Gastroenterol 2000;95:2225-32.

36. Van Leerdam ME. Epidemiology of acute upper gastrointestinal bleeding. Best Pract Res Clin Gastroenterol 2008;22:209-24.

37. Targownik LE, Nabalamba A. Trends in management and outcomes of acute nonvariceal upper gastrointestinal bleeding: 1993-2003. Clin Gastroenterol Hepatol 2006;4:1459-66.

38. Barkun A, Sabbah S, Enns R, et al. The Canadian Registry on Nonvariceal Upper Gastrointestinal Bleeding and Endoscopy (RUGBE): Endoscopic hemostasis and proton pump inhibition are associated with improved outcomes in a real-life setting Am J Gastroenterol 2004;99:1238-46.

39. Ateş F, Karıncaoğlu M, Aladağ M. Varis dışı kanamalı 524 olgunun değerlendirilmesi. Journal of Inonu University Medical 2008;15:14-8.

40. Karadağ F. Üst gastrointestinal kanamalı hastaların genel değerlendirilmesi. Uzmanlık tezi, Istanbul: Göztepe Eğitim ve Araștırma Hastanesi, Aile Hekimliği Bölümü, 2008;45-50.

41. Rockall TA, Logan RF, Devlin HB, Northfield TC. Influencing the practice and outcome in acute upper gastrointestinal haemorrhage. Steering Committee of the National Audit of Acute Upper Gastrointestinal Haemorrhage. Gut 1997;41:606-11.

42. Romagnuolo J, Barkun AN, Enns R, et al. Simple clinical predictors may obviate urgent endoscopy in selected patients with nonvariceal upper gastrointestinal tract bleeding. Arch Intern Med 2007;167:265-70.

43. Jensen DM, Kovacs TO, Jutabha R, et al. Randomized trial of medical or endoscopic therapy to prevent recurrent ulcer hemorrhage in patients with adherent clots. Gastroenterology 2002;123:407-13.

44. Bleau BL, Gostout CJ, Sherman KE, et al. Recurrent bleeding from peptic ulcer associated with adherent clot: a randomized study comparing endoscopic treatment with medical therapy. Gastrointest Endosc 2002;56:1-6. 